\title{
natureouTLOoK MELANOMA
}

20 November 2014 / Vol 515 / Issue No 7527

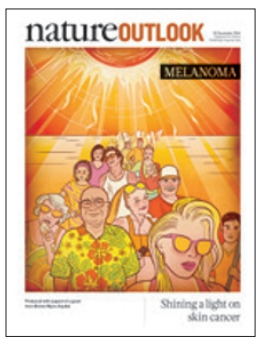

Cover art: Susan Burghart

\section{Editorial}

Herb Brody,

Michelle Grayson,

Brian Owens,

Kathryn Miller,

Nick Haines

Art \& Design

Wesley Fernandes,

Mohamed Ashour,

Kate Duncan,

Denis Mallet

Production

Karl Smart,

lan Pope,

Robert Sullivan

Sponsorship

Janice Stevenson,

Samantha Morley

Marketing

Hannah Phipps

Project Manager

Anastasia Panoutsou

Art Director

Kelly Buckheit Krause

Publisher

Richard Hughes

Chief Magazine Editor

Rosie Mestel

Editor-in-Chief

Philip Campbell
$\mathrm{M}$ elanoma is the deadliest form of skin cancer and strikes tens of thousands of people around the world each year. The number of cases is rising faster than any other type of solid cancer (see page S110).

It is usually caused by too much exposure to the Sun's ultraviolet radiation. But the link between sunshine and melanoma is not as straightforward as it seems. The pattern of exposure can be just as important as the total amount of ultraviolet radiation that reaches the skin (S112).

Because the cause of melanoma is so well known, it seems strange that the incidence keeps rising. But although we have the tools to prevent the disease, we do not always use them (S117 and S126), and not enough people take action to reduce their risk. Australia, which has the highest rate of melanoma, has been slowly getting the disease under control and may have some lessons to teach the rest of the world (S114).

For those hoping to skip the demands of a sun-safe routine and simply take a sunscreen pill instead, the news is not so good. There is little evidence that any drug will be able to offer full sun protection (S124).

For those who do develop melanoma, however, the chances of recovery are rising. Targeted treatments and therapies that use the body's own immune system have been developed in the past few years (S118).

Although melanoma is primarily an affliction of the fairskinned, it can also strike those with a darker complexion. The disease in black populations seems to have a different biology to that in lighter-skinned people, and is also particularly deadly (S121).

We are pleased to acknowledge that this Outlook was produced with support of a grant from Bristol-Myers Squibb. As always, Nature retains sole responsibility for all editorial content.

\section{Brian Owens}

Contributing Editor
Nature Outlooks are sponsored supplements that aim to stimulate interest and debate around a subject of interest to the sponsor, while satisfying the editorial values of Nature and our readers' expectations. The boundaries of sponsor involvement are clearly delineated in the Nature Outlook Editorial guidelines available at delineated in the Nature
go.nature.com/e4dwzw

CITING THE OUTLOOK

Cite as a supplement to Nature, for example, Nature Vol. XXX, No. XXXX Suppl., Sxx-Sxx (2014).

VISIT THE OUTLOOK ONLINE

The Nature Outlook Melanoma supplement can be found at

http://www.nature.com/nature/outlook/melanoma

It features all newly commissioned content as well as a selection of

relevant previously published material.
All featured articles will be freely available for 6 months. SUBSCRIPTIONS AND CUSTOMER SERVICES For UK/Europe (excluding Japan): Nature Publishing Group, Subscriptions, Brunel Road, Basingstoke, Hants, RG21 6XS, UK. Tel: +44 (0) 1256329242. Subscriptions and customer services for Americas - including Canada, Latin America and the Caribbean: Nature Publishing Group, 75 Varick St, 9th floor, New York, NY 10013-1917, USA. Tel: +1 8663637860 (US/Canada) or +1 212726 9223 (outside US/Canada). Japan/China/Korea: Nature Publishing Group - Asia-Pacific, Chiyoda Building 5-6th Floor, 2-37 Ichigaya Tamachi, Shinjuku-ku, Tokyo, 162-0843, Japan. Tel: +81332678751. CUSTOMER SERVICES

Feedback@nature.com

Copyright $\odot 2014$ Nature Publishing Group

\section{CONTENTS}

S110 AETIOLOGY

The cancer that rises with the sun

The growth and spread of melanoma

S112 RISK FACTORS

Riddle of the rays

There is more to melanoma risk than

time spent in the sun

S114 PREVENTION

Lessons from a sunburnt country

Stay safe the Australian way

S117 PERSPECTIVE

Catch melanoma early

Susan M Swetter and Alan C Geller call for routine skin checks

\section{S118 DRUG DEVELOPMENT}

A chance of survival

The search for targeted treatments pays off

S121 SKIN COLOUR

No hiding in the dark

Why do black people get melanoma?

S124 PROTECTION

The sunscreen pill

Tablets will not keep you safe in the sun

S126 PERSPECTIVE

Protect the USA from UVA

Michael J Werner says it is time the FDA

started approving stronger sunscreens

\section{COLLECTION}

S127 Smart therapeutic strategies in immuno-oncology

A M M Eggermont \& C Robert

S129 Melanoma metastasis: new concepts and evolving paradigms WE Damsky et al.

S139 Stat3-targeted therapies overcome the acquired resistance to vemurafenib in melanomas F Liu et al.

S148 Melanoma exosomes educate bone marrow progenitor cells toward a prometastatic phenotype through MET H Peinado et al. 